\title{
Penerapan Metode Support Vector Machine pada Sistem Deteksi Intrusi secara Real-time
}

\author{
Agustinus Jacobus* ${ }^{1}$, Edi Winarko ${ }^{2}$ \\ ${ }^{1}$ Program Studi S2 Ilkom, FMIPA, UGM, Yogyakarta \\ ${ }^{2}$ Jurusan Ilmu Komputer dan Elektronika, FMIPA UGM, Yogyakarta \\ e-mail: *1 a.jacobus@mail.ugm.ac.id ${ }^{2}$ ewinarko@ugm.ac.id
}

\begin{abstract}
Abstrak
Sistem deteksi intrusi adalah sebuah sistem yang dapat mendeteksi serangan atau intrusi dalam sebuah jaringan atau sistem komputer, umum pendeteksian intrusi dilakukan dengan membandingkan pola lalu lintas jaringan dengan pola serangan yang diketahui atau mencari pola tidak normal dari lalu lintas jaringan. Pertumbuhan aktivitas internet meningkatkan jumlah paket data yang harus dianalisis untuk membangun pola serangan ataupun normal, situasi ini menyebabkan kemungkinan bahwa sistem tidak dapat mendeteksi serangan dengan teknik yang baru, sehingga dibutuhkan sebuah sistem yang dapat membangun pola atau model secara otomatis.

Penelitian ini memiliki tujuan untuk membangun sistem deteksi intrusi dengan kemampuan membuat sebuah model secara otomatis dan dapat mendeteksi intrusi dalam lingkungan real-time, dengan menggunakan metode support vector machine sebagai salah satu metode data mining untuk mengklasifikasikan audit data lalu lintas jaringan dalam 3 kelas, yaitu: normal, probe, dan DoS. Data audit dibuat dari preprocessing rekaman paket data jaringan yang dihasilkan oleh Tshark.

Berdasar hasil pengujian, sistem dapat membantu sistem administrator untuk membangun model atau pola secara otomatis dengan tingkat akurasi dan deteksi serangan yang tinggi serta tingkat false positive yang rendah. Sistem juga dapat berjalan pada lingkungan real-time.
\end{abstract}

Kata kunci-deteksi intrusi, klasifikasi, preprocessing, support vector machine

Intrusion detection system is a system for detecting attacks or intrusions in a network or computer system, generally intrusion detection is done with comparing network traffic pattern with known attack pattern or with finding unnormal pattern of network traffic. The raise of internet activity has increase the number of packet data that must be analyzed for build the attack or normal pattern, this situation led to the possibility that the system can not detect the intrusion with a new technique, so it needs a system that can automaticaly build a pattern or model.

This research have a goal to build an intrusion detection system with ability to create a model automaticaly and can detect the intrusion in real-time environment with using support vector machine method as a one of data mining method for classifying network traffic audit data in 3 classes, namely: normal, probe, and DoS. Audit data was established from preprocessing of network packet capture files that obtained from Tshark.

Based on the test result, the system can help system administrator to build a model or pattern automaticaly with high accuracy, high attack detection rate, and low false positive rate. The system also can run in real-time environment.

Keywords - intrusion detection, classification, preprocessing, support vector machine 


\section{PENDAHULUAN}

Cistem deteksi intrusi adalah sebuah sistem untuk mendeteksi serangan atau intrusi pada suatu jaringan atau sistem komputer, umumnya pendeteksian intrusi dilakukan dengan mencocokkan pola lalu lintas jaringan dengan pola serangan yang telah diketahui (misuse) atau dengan mencari pola lalu lintas jaringan yang tidak normal (anomaly). Untuk membangun sebuah sistem deteksi intrusi yang efektif dengan metode anomaly detection seorang analis mengandalkan intuisi dan pengalaman untuk memilih ukuran statistik dan untuk pendeteksian intrusi dan untuk misuse detection seorang analis pertama kali harus menganalisis dan mengkategorikan skenario serangan, kerentanan sistem, dan membuat aturan dan pola-pola yang sesuai dengan intrusi. Karena dilakukan secara manual dan maka IDS yang telah ada memiliki keterbatasan dalam kemampuan beradaptasi pada jenis serangan baru [1].

Perkembangan aktivitas internet dan serangan terhadap sistem komputer yang semakin meningkat, menyebabkan data yang harus dianalisis menjadi sangat besar dan tentunya ini menjadi masalah bagi seorang analis paket data untuk memilah data dan membentuk skenario dari data yang terkumpul tersebut, sehingga muncul kecurigaan bahwa sistem deteksi intrusi yang ada tidak dapat mendeteksi serangan-serangan yang berbahaya yang dilakukan dengan teknik yang baru, tersembunyi atau keduanya. Permasalahan ini menyebabkan diperlukan sebuah sistem yang dapat membantu analis dalam proses analisis data dan dapat menemukan serangan yang tidak dapat ditemukan oleh analis atau sensor [2].

Penerapan metode-metode data mining untuk mendeteksi intrusi dapat menjadi solusi dari permasalahan peningkatan jumlah data yang besar karena memiliki keunggulan dalam memproses system logs atau audit data dalam jumlah yang besar dan metode data mining dapat membantu mengintegrasikan kedua teknik pendeteksian intrusi (anomaly dan misuse). Aplikasi data mining juga dapat menemukan suatu pola yang rutin dalam dataset yang besar dan dapat memberikan suatu solusi untuk masalah reduksi data pada dataset yang besar sehingga mempermudah bagi analis untuk mengidentifikasi data dan memberikan analisis yang lebih efisien [3].

Support vector machine (SVM) sebagai salah satu metode dari data mining terbukti memiliki tingkat akurasi yang tinggi dalam mengklasifikasikan pola-pola paket data jaringan, ini dibuktikan oleh beberapa penelitian yang mempergunakan dataset DARPA KDD'99 yang dibuat oleh Lincoln Lab [4][5]. Berdasar dari hasil penelitian-penelitian tersebut maka SVM dinilai tepat untuk diimplementasikan dalam penelitian ini.

\section{METODE PENELITIAN}

\subsection{Analisa}

Data yang digunakan untuk mendeteksi intrusi adalah data rekaman lalu lintas paket data dalam jaringan komputer yang direkam menggunakan aplikasi network monitoring (tshark) dalam bentuk pcap files. Sistem yang dibangun dalam penelitian ini melakukan pengolahan rekaman paket data jaringan (pcap file) kedalam bentuk data audit (connection record). Kemampuan pendeteksian intrusi dari sistem yang dibangun masih terbatas pada jenis intrusi yang dapat diketahui lewat analisis informasi header paket data. Connection record yang terbentuk diklasifikasikan kedalam 3 kelas yaitu: normal untuk aktivitas pengaksesan layanan sistem komputer secara normal dan sifatnya tidak mengganggu, probe untuk aksi intrusi yang bertujuan mengumpulkan informasi sumber daya jaringan atau sistem komputer, dan DoS (Denial of Service) untuk aksi intrusi yang dapat mengganggu availability dari layanan sebuah sistem komputer.

Pembentukan data audit atau connection record memiliki 2 tujuan yaitu untuk keperluan data training dan pendeteksian intrusi. Pembentukan connection record untuk data training pengklasifikasiannya oleh sistem administrator dengan memberikan label atau kelas

IJCCS Vol. 8, No. 1, January 2014: 13 - 24 
pada tiap record yang terbentuk berdasar kategori serangan atau intrusi yang dilakukan, data training digunakan dalam proses training untuk memperoleh model yang digunakan dalam proses pengklasifikasian. Pada pembentukan connection record untuk pendeteksian intrusi tidak dilakukan penetapan label atau kelas dilakukan oleh proses pengklasifikasian berdasar model yang terbentuk dari proses training.

\subsection{Arsitektur dan Rancangan Sistem}

Desain arsitektur sistem yang dibangun diperlihatkan pada Gambar 1. Sistem (SVMNIDS) memperoleh masukan dari aplikasi network monitoring (tshark) berupa pcap file dan diterima oleh bagian preprocessing untuk dilakukan ekstraksi data dan membentuk membentuk fitur-fitur connection record. Ada perbedaan untuk keluaran dari bagian preprocessing yaitu: connection record yang dilabel berdasar kelas dan tidak dilabel. Connection record yang dilabel digunakan untuk keperluan training sistem dan terbentuk pada saat pengumpulan data training, sedangkan connection record yang tidak dilabel digunakan untuk mendeteksi intrusi dalam jaringan.

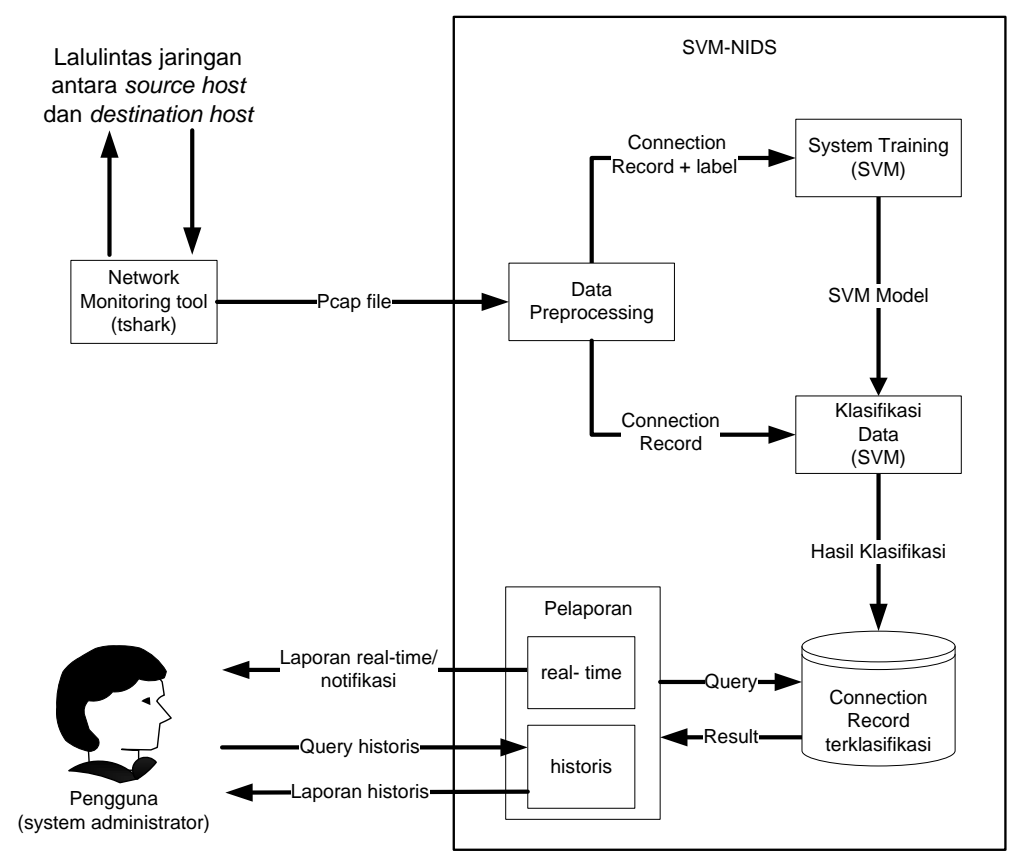

Gambar 1 Rancangan arsitektur sistem

Untuk connection record yang terlabel digunakan oleh bagian sistem training untuk melakukan training sistem atau analisis dari data training yang dihasilkan dari proses preprocessing dengan metode SVM. Adapun tujuan dari proses training itu sendiri adalah mencari model atau fungsi yang menggambarkan dan membedakan kelas-kelas data atau konsep untuk memprediksikan atau mengklasifikasikan kelas dari suatu objek yang kelas labelnya belum diketahui [6]. Model yang diperoleh dari bagian sistem training digunakan oleh bagian klasifikasi data untuk mengklasifikasikan data connection record yang belum terlabel atau untuk mendeteksi aksi-aksi intrusi. Metode yang digunakan untuk proses training dan klasifikasi adalah support vector machine (SVM), dan untuk penerapannya digunakan fungsifungsi yang ada dalam library libsvm. Hasil klasifikasi disimpan dalam basis data connection record terklasifikasi untuk digunakan oleh bagian pelaporan.

Bagian pelaporan bertugas untuk melakukan query ke dalam basis data dan melaporkannya kepada pengguna yaitu sistem administrator dengan format HTML. Pelaporan 
dilakukan dalam 2 cara yaitu secara real-time dan historis. Pelaporan real-time melaporkan informasi paket data yang melewati jaringan secara berkala dan memberikan peringatan kepada sistem administrator ketika terjadi intrusi, sedangkan pelaporan historis memberikan laporan berdasar query dari pengguna dan digunakan untuk melihat kejadian-kejadian di masa yang lalu.

Untuk gambaran lebih jelas dari proses preprocessing, training sistem dan klasifikasi yang terjadi dalam sistem dapat dilihat pada Gambar 2.

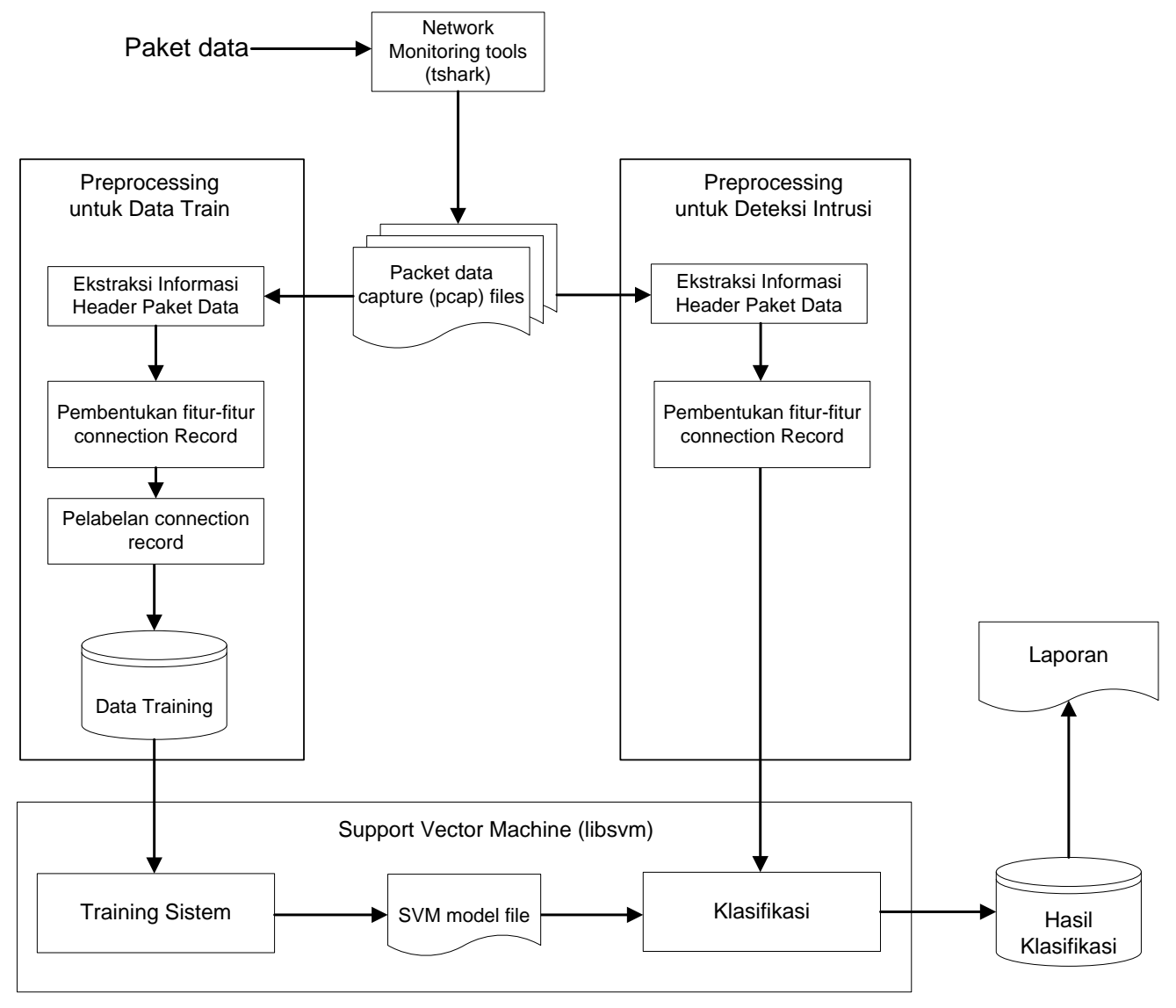

Gambar 2 Gambaran umum sistem

Preprocessing dilakukan pada dua keadaan, keadaan pertama bertujuan membentuk data training dan yang kedua bertujuan untuk mendeteksi intrusi. Preprocessing untuk data training dibentuk selama masa pengumpulan data training atau selama masa dilakukan simulasi intrusi dan komunikasi data normal yang dilakukan oleh sistem administrator, selama simulasi berlangsung data yang terbentuk setelah proses ekstraksi dan proses pembentukan connection record diberi label sesuai kategori simulasi yang berlangsung. Data training yang terbentuk disimpan dalam basis data pada tabel data training untuk digunakan dalam proses training sistem. Preprocessing untuk keperluan pendeteksian intrusi tidak mengalami proses pelabelan, conection record yang terbentuk menjadi masukan dalam proses klasifikasi.

Pada proses preprocessing, pcap file sebelum menjadi connection record melewati beberapa tahap yaitu ekstraksi informasi header paket data, pembentukan fitur-fitur connection record dan pelabelan connection record pada preprocessing untuk data training. Tahap ekstraksi informasi header paket data membaca pcap file yang dihasilkan oleh tshark untuk mendapatkan informasi header paket data dengan protokol TCP, UDP, dan ICMP. Informasiinformasi yang diambil ditampilkan pada Tabel 1.

IJCCS Vol. 8, No. 1, January 2014: 13 - 24 
Tabel 1 Informasi header paket data TCP, UDP, ICMP

\begin{tabular}{|l|l|l|}
\hline No. & \multicolumn{1}{|c|}{$\begin{array}{c}\text { Informasi Header } \\
\text { paket data }\end{array}$} & \multicolumn{1}{|c|}{ Penjelasan } \\
\hline 1. & Time & Waktu kedatangan paket data. \\
\hline 2. & IP source & Alamat IP host pengirim \\
\hline 3. & IP destination & Alamat IP host penerima \\
\hline 4 & IP Protocol & $\begin{array}{l}\text { Mengindikasikan tipe protokol yang digunakan (UDP, } \\
\text { TCP, ICMP) }\end{array}$ \\
\hline 5. & TCP source port & $\begin{array}{l}\text { Nomor } \text { port dari source host yang mengirimkan } \\
\text { segmen TCP bersangkutan }\end{array}$ \\
\hline 6. & TCP destination port & $\begin{array}{l}\text { Nomor } \text { port } \text { dari destination host yang menerima } \\
\text { segmen TCP bersangkutan }\end{array}$ \\
\hline 7. & TCP length & Mengindikasikan panjang segmen TCP yang dikirim \\
\hline 8. & TCP stream & Mengindikasikan nomor stream/connection dari TCP \\
\hline 9. & UDP source port & $\begin{array}{l}\text { Nomor } \text { port dari source host yang mengirimkan } \\
\text { segmen UDP bersangkutan. }\end{array}$ \\
\hline 10. & UDP destination port & $\begin{array}{l}\text { Nomor } \text { port dari destination host yang menerima } \\
\text { segmen UDP bersangkutan }\end{array}$ \\
\hline 11. & UDP length & Mengindikasikan panjang segmen UDP yang dikirim. \\
\hline 12. & Frame length & Mengindikasikan panjang frame yang dikirim. \\
\hline 13. & ICMP sequence & Nomor sequence dari paket ICMP yang dikirim \\
\hline 14. & ICMP type & Mengindikasikan tipe ICMP yang dikirimkan \\
\hline & &
\end{tabular}

Berdasar informasi header paket data hasil ekstraksi dibentuk data audit (connection record) dengan fitur-fitur yang ditampilkan pada Tabel 2.

Tabel 2 Fitur-fitur connection record

\begin{tabular}{|l|l|l|}
\hline No. & \multicolumn{1}{|c|}{ Fitur } & \multicolumn{1}{c|}{ Penjelasan } \\
\hline 1. & Timestamp & Waktu kedatangan paket \\
\hline 2. & Ip_src & Alamat IP source host \\
\hline 3. & Ip_dest & Alamat IP destination host \\
\hline 4. & Protocol & Tipe protokol (ICMP, TCP, UDP). \\
\hline 5. & Service_port & Nomor port dari destination host dalam koneksi \\
\hline 6. & Src_bytes & $\begin{array}{l}\text { Jumlah rata-rata byte, termasuk informasi } \\
\text { header yang diterima oleh destination host }\end{array}$ \\
\hline 7. & Dst_bytes & $\begin{array}{l}\text { Jumlah rata-rata byte termasuk informasi } \\
\text { header yang diterima oleh source host }\end{array}$ \\
\hline 8. & Count & $\begin{array}{l}\text { Fitur yang mengindikasikan jumlah koneksi } \\
\text { pada host yang sama dalam 2 detik terakhir }\end{array}$ \\
\hline 9. & Srv_count & $\begin{array}{l}\text { Jumlah koneksi pada service sama untuk } \\
\text { koneksi yang sama dalam 2 detik terakhir }\end{array}$ \\
\hline 10. & Dst_host_srv_count & $\begin{array}{l}\text { Jumlah koneksi ke tujuan yang sama dan } \\
\text { service yang sama dalam rentang 100 } \\
\text { connection record terakhir }\end{array}$ \\
\hline 11. & Dst_host_same_src_port_rate & $\begin{array}{l}\text { Persentase jumlah koneksi ke destination host } \\
\text { dengan nomor } \text { source port yang sama dalam } \\
\text { rentang 100 connection record terakhir }\end{array}$ \\
\hline
\end{tabular}

Fitur utama dari connection record yang terbentuk adalah fitur src_bytes, dst_bytes, count, srv_count, dst_host_srv_count, dst_host_same_src_port_rate. Fitur-fitur utama adalah fitur-fitur yang dipergunakan dalam proses training sistem dan pengklasifikasian data. Fitur 
timestamp, ip_src, ip_dest, protocol, service_port tidak digunakan pada proses training sistem ataupun klasifikasi data, fitur-fitur ini merupakan fitur tambahan yang digunakan untuk kelengkapan informasi pada saat pelaporan kepada pengguna.

Pembentukan fitur-fitur connection record dilakukan secara complete dan incomplete, dimana connection record dibentuk secara complete ketika memiliki durasi koneksi kurang dari 2 detik dan dibentuk secara incomplete ketika memiliki durasi koneksi lebih dari 2 detik [7]. Untuk menyatakan 1 koneksi pada paket data dengan protokol TCP dapat berpatokan pada informasi nomor TCP stream dan untuk paket data dengan protokol UDP dan ICMP karena bersifat connectionless protocol maka setiap paket data dapat diperlakukan sebagai 1 koneksi, kecuali untuk koneksi yang memiliki response seperti DNS request dan ICMP echo request maka request dan response atau reply harus diperlakukan sebagai 1 koneksi bukan 2 koneksi. Untuk menyatakan 1 koneksi pada protokol UDP dapat berpatokan pada informasi destination host, source host, destination port dan source port, sedangkan untuk protokol ICMP dapat berpatokan pada informasi ICMP sequence dimana ICMP dengan nomor sequence yang sama dinyatakan sebagai 1 koneksi.

\subsection{Implementasi Sistem}

Gambar 3 adalah hasil implementasi dari preprocessing untuk pembentukan data training dimana selama proses pengumpulan data training bagian System Status akan menunjukkan "Data Train Capture Run" yang berarti sistem sedang berjalan dengan modus pengumpulan data training. Selama proses ini tidak terjadi pendeteksian intrusi, seluruh connection record yang terbentuk diklasifikasikan berdasar label yang ditetapkan pengguna pada bagian Record Class type. Data training yang terkumpul saat pengumpulan data training sifatnya masih kotor karena mengandung banyak duplikasi data. Untuk membersihkan data training dari duplikasi data dilakukan lewat button Save to Training Data Tabel, yang sekaligus menyimpan data training dalam tabel data_training secara keseluruhan atau data tertentu saja berdasar informasi yang ditetapkan pada selection list Intruder/source host.

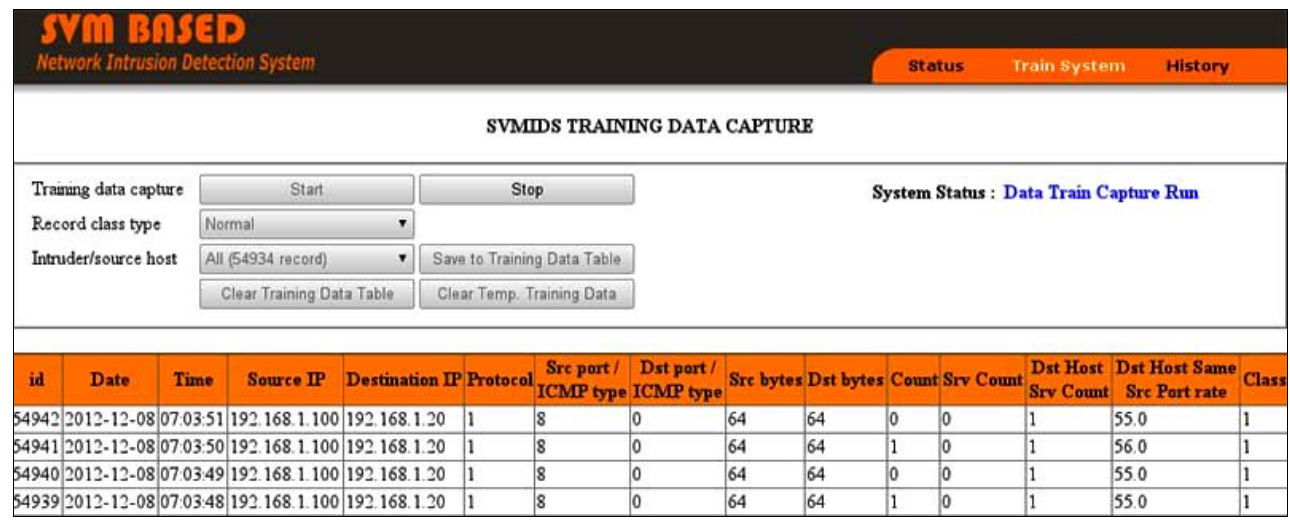

Gambar 3 Tampilan proses pengumpulan data training.

Gambar 4 menampilkan hasil implementasi untuk proses training sistem dimana pada bagian ini juga dapat dilakukan pengujian dari model yang dihasilkan dari proses training. Proses training meliputi penetapan parameter libsvm berupa parameter $C$, tipe kernel dan parameter-parameter kernel. Pengujian dapat dilakukan dengan 2 skenario yaitu:

1. Pengujian dengan metode $k$-fold cross validation,dengan cara membagi data training sebanyak $k$ bagian, kemudian $k-1$ bagian digunakan sebagai data untuk training sistem dan sisanya digunakan sebagai data test. pengujian ini dilakukan sebanyak $k$ kali dengan mengganti-ganti partisi yang berfungsi sebagai data training dan data test.

2. Pengujian dengan menggunakan eksternal data test dilakukan dengan menggunakan data test yang dibuat tersendiri diluar dari data training, sistem terlebih dilatih menggunakan

IJCCS Vol. 8, No. 1, January 2014: 13 - 24 
keseluruhan data training, dan kemudian eksternal data test diklasifikasi dan kemudian kelas hasil klasifikasi di bandingkan dengan kelas dari data test yang sebenarnya.

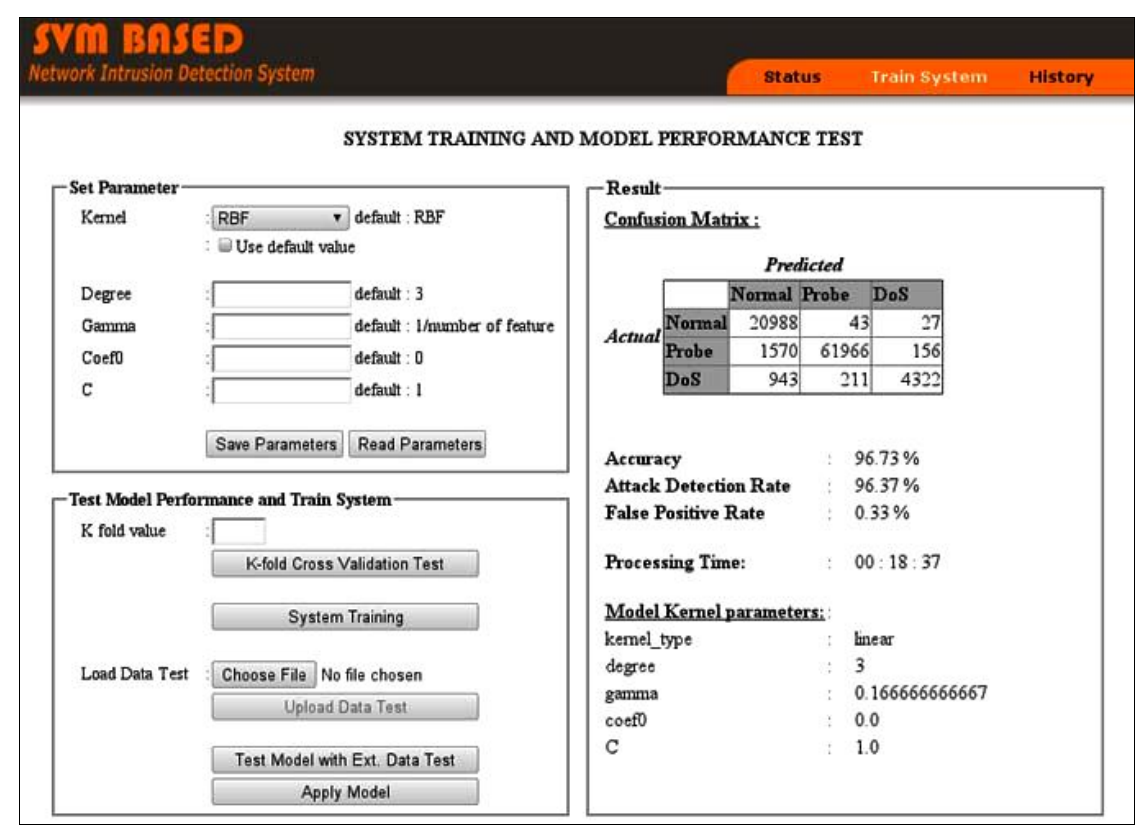

Gambar 4 Tampilan proses training dan pengujian model.

Hasil pengujian model ditampilkan pada bagian Result dalam bentuk confusion matrix untuk menunjukkan perbandingan jumlah connection record hasil klasifikasi (predicted) dan kelas yang sebenarnya (actual), tingkat akurasi pengklasifikasian (accuracy), tingkat deteksi serangan (attack detection rate) dan tingkat false positive (false positive rate). Selain informasi utama berupa hasil pengujian ditampilkan juga informasi tambahan berupa waktu proses (processing time) dan informasi parameter dari model yang diuji.

Gambar 5 adalah tampilan dari hasil implementasi laporan real-time, dimana bagian system status akan menunjukan indikasi RUN ketika sistem sedang berjalan untuk mendeteksi serangan, button ON/OFF berfungsi untuk menjalankan dan menghentikan sistem dan selection list Show Record Type berfungsi untuk melakukan penyaringan record yang ditampilkan.

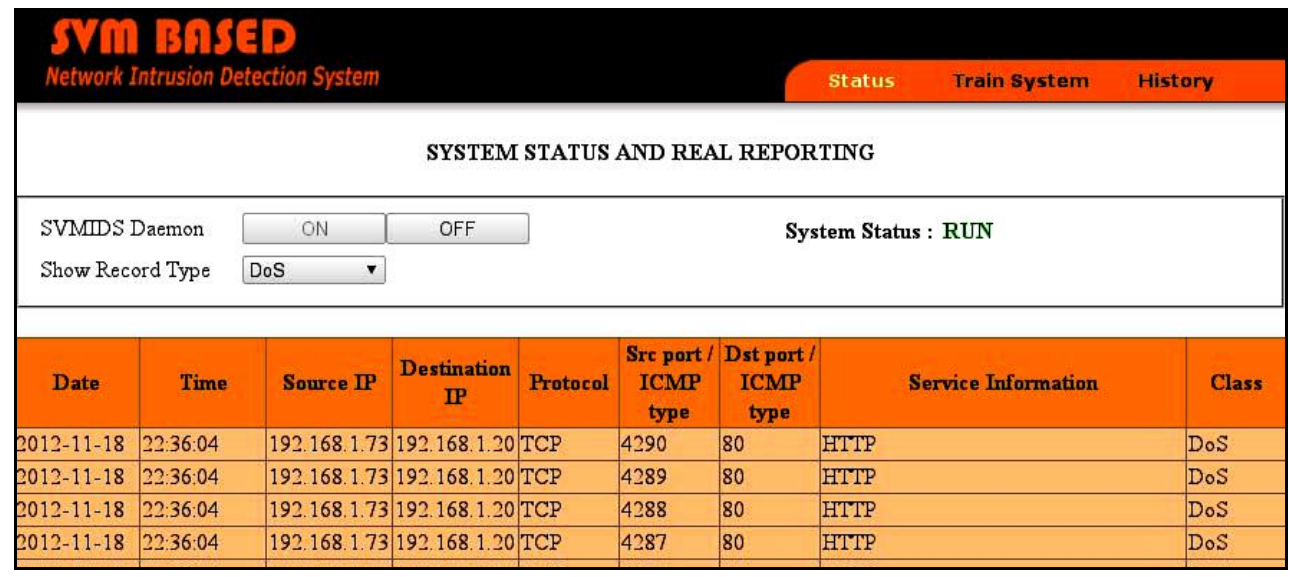

Gambar 5 Laporan real-time

Gambar 6 memperlihatkan hasil implementasi untuk pelaporan historis dimana query yang diinputkan oleh pengguna adalah berupa tanggal (Date) dan jam (Hour) dari waktu 
kejadian yang ingin dilihat, dan sama seperti pada pelaporan real-time show record type digunakan untuk melakukan penyaringan dari record yang ditampilkan.

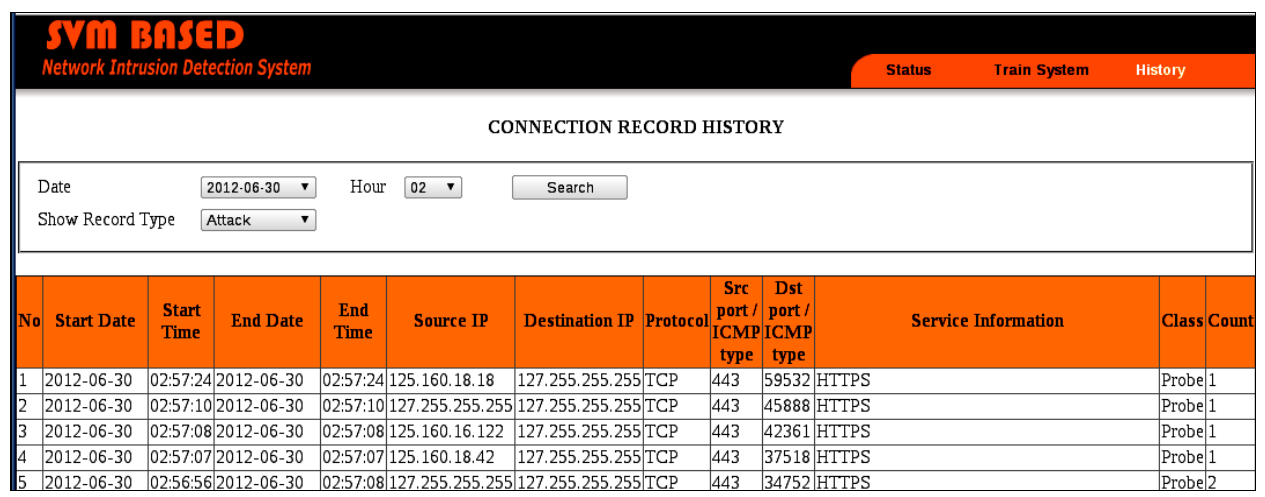

Gambar 6 Tampilan halaman connection record history

\section{HASIL DAN PEMBAHASAN}

Pengujian dari sistem yang dibangun dilakukan dengan cara melakukan aksi intrusi dan komunikasi secara normal ke sebuah sistem yang menjadi target. Connection record yang terbentuk selama aksi intrusi digunakan untuk data training dan pengujian secara offline maupun real-time. Performansi dari sistem didasarkan pada tiga kriteria yaitu: tingkat akurasi yang ditunjukan pada persamaan (1), tingkat deteksi (ADR) pada persamaan (2) dan tingkat false positive (FPR) ditunjukan pada persamaan (3). Performansi dikatakan baik apabila memiliki tingkat akurasi dan tingkat deteksi yang tinggi, serta tingkat false positive yang rendah.

$$
\begin{aligned}
& \text { Akurasi }=\frac{\text { Jumlah data terklasifikasi benar }}{\text { Total jumlah data test }} 100 \% \\
& A D R=\frac{\text { Jumlah data serangan terdeteksi }}{\text { Total jumlah data serangan }} 100 \% \\
& F P R=\frac{\text { Jumlah data kelas normal terklasifikasi salah }}{\text { Total jumlah data kelas normal }} 100 \%
\end{aligned}
$$

\subsection{Pengujian Secara Offline}

Pengujian secara offline bertujuan mencari model terbaik yang dapat digunakan untuk mendeteksi intrusi. Pengujian secara offline dengan metode $k$-fold cross validation mempergunakan dataset yang terbentuk dari aksi-aksi intrusi yang bertujuan membentuk data training lewat fasilitas training data capture dan eksternal data test yaitu dataset lain yang dibentuk dengan cara yang sama dengan pembentukan data training sebelumnya. Adapun dataset yang terbentuk dalam penelitian ini (dataset Simulasi) memiliki 90224 connection record yang terdiri atas: 21058 record kelas normal, 63690 record kelas probe, dan 5476 record kelas DoS, sedangkan untuk data test Simulasi memiliki 17535 connection record yang terdiri atas 14217 record kelas normal, 533 record kelas probe, dan 2785 record kelas DoS.

Tabel 3 memperlihatkan hasil pengujian dataset simulasi dengan metode $k$-fold cross validation. Dari hasil pengujian offline dengan metode $k$-fold cross validation dipilih model terbaik adalah model dengan tipe kernel polinomial $\mathrm{C}=100$, karena memiliki tingkat akurasi

IJCCS Vol. 8, No. 1, January 2014: 13 - 24 
tertinggi dan tingkat deteksi yang tinggi juga serta tingkat false positive yang rendah pada nilai $\mathrm{C}=100$.

Tabel 3 Performansi model pada dataset simulasi

\begin{tabular}{|c|c|c|c|c|c|}
\hline \multirow{2}{*}{$\begin{array}{l}\text { Parameter } \\
C\end{array}$} & \multirow{2}{*}{ Kriteria } & \multicolumn{4}{|c|}{ Tipe kernel } \\
\hline & & Linear & RBF & Polinomial & Sigmoid \\
\hline \multirow{3}{*}{1} & Akurasi & 96,73 & 95,86 & 96,0 & 94,74 \\
\hline & ADR & 96,37 & 95,01 & 95,18 & 95,30 \\
\hline & FPR & 0,33 & 0,27 & 0,20 & 5,99 \\
\hline \multirow{3}{*}{5} & Akurasi & 97,52 & 97,17 & 97,25 & 94,14 \\
\hline & ADR & 97,42 & 96,82 & 96,99 & 94,87 \\
\hline & FPR & 0,34 & 0,18 & 0,23 & 7,73 \\
\hline \multirow{3}{*}{10} & Akurasi & 97,72 & 97,74 & 97,58 & 93,82 \\
\hline & ADR & 97,70 & 97,22 & 97,37 & 94,85 \\
\hline & FPR & 0,47 & 0,25 & 0,30 & 9,07 \\
\hline \multirow{3}{*}{25} & Akurasi & 97,94 & 98,09 & 98,16 & 93,25 \\
\hline & ADR & 98,01 & 97,63 & 97,74 & 94,36 \\
\hline & FPR & 0,55 & 0,36 & 0,42 & 9,89 \\
\hline \multirow{3}{*}{50} & Akurasi & 98,05 & 98,29 & 98,34 & 92,50 \\
\hline & ADR & 98,17 & 97,90 & 97,98 & 94,28 \\
\hline & FPR & 0,61 & 0,41 & 0,50 & 12,42 \\
\hline \multirow{3}{*}{100} & Akurasi & 98,13 & 98,43 & 98,46 & 92,98 \\
\hline & ADR & 98,30 & 98,11 & 98,16 & 94,12 \\
\hline & FPR & 0,64 & 0,51 & 0,56 & 10,24 \\
\hline
\end{tabular}

Tabel 4 menunjukan performansi model dari pengujian dengan menggunakan eksternal data test.

Tabel 4 Performansi model pada pengklasifikasian data test simulasi

\begin{tabular}{|c|l|l|l|l|l|}
\hline \multirow{2}{*}{$\begin{array}{l}\text { Parameter } \\
\text { Criteria }\end{array}$} & \multicolumn{4}{|c|}{ Tipe kernel } \\
\cline { 2 - 6 } & & Linear & RBF & polinomial & Sigmoid \\
\hline \multirow{4}{*}{1} & Akurasi & 90,14 & 89,40 & 89,81 & 88,08 \\
\cline { 2 - 6 } & ADR & 66,60 & 68,80 & 67,10 & 72,23 \\
\cline { 2 - 6 } & FPR & 3,48 & 5,04 & 4,19 & 7,45 \\
\hline \hline \multirow{4}{*}{5} & Akurasi & 85,22 & 89,48 & 89,68 & 83,76 \\
\cline { 2 - 6 } & ADR & 48,93 & 64,40 & 63,40 & 71,35 \\
\cline { 2 - 6 } & FPR & 5,94 & 4,11 & 3,714 & 12,49 \\
\hline \hline \multirow{3}{*}{$\mathbf{2 5}$} & Akurasi & 79,18 & 88,29 & 84,12 & 84,03 \\
\cline { 2 - 6 } & ADR & 44,23 & 64,22 & 66,16 & 68,97 \\
\cline { 2 - 6 } & FPR & 11,67 & 5,48 & 6,55 & 11,78 \\
\hline \hline \multirow{3}{*}{50} & Akurasi & 66,87 & 82,89 & 75,98 & 83,72 \\
\cline { 2 - 6 } & ADR & 19,46 & 65,89 & 66,72 & 68,50 \\
\cline { 2 - 6 } & FPR & 20,57 & 12,37 & 14,63 & 12,06 \\
\hline \hline \multirow{3}{*}{100} & Akurasi & 63,87 & 75,78 & 69,02 & 83,61 \\
\cline { 2 - 6 } & ADR & 19,87 & 66,66 & 67,27 & 68,42 \\
\cline { 2 - 6 } & FPR & 24,32 & 21,17 & 22,21 & 12,18 \\
\cline { 2 - 6 } & Akurasi & 61,90 & 70,61 & 64,16 & 83,57 \\
\cline { 2 - 6 } & ADR & 20,11 & 66,48 & 68,56 & 68,42 \\
\cline { 2 - 5 } & FPR & 26,81 & 27,40 & 27,62 & 12,22 \\
\hline \hline
\end{tabular}


Dari pengujian ini diperoleh model terbaik adalah model dengan tipe kernel linear pada nilai $C=1$ dengan pertimbangan tingkat akurasi dari model ini adalah yang tertinggi dari model yang lain disertai tingkat deteksi yang tinggi serta tingkat false positive yang rendah pada nilai $\mathrm{C}=1$.

\subsection{Pengujian Secara Real-Time}

Pengujian secara real-time dilakukan dengan menguji 2 model yang diperoleh dari pengujian secara offline pada situasi yang nyata. Sistem dilatih dengan menggunakan parameterparameter dari 2 model terbaik hasil pengujian offline, kemudian diaplikasikan untuk mengklasifikasikan connection record atau mendeteksi aksi intrusi yang dilakukan pada sebuah sistem komputer, 2 model tersebut adalah: model dengan tipe kernel polinomial $C=100$ (M1) dan model dengan tipe kernel linear $C=1$ (M2).

Tabel 5 menunjukan perbandingan performansi dari kedua model ketika dilakukan aksi intrusi dan komunikasi normal ke sebuah sistem komputer. Dari Tabel 5 dapat dilihat bahwa performansi dari model 2 lebih baik daripada model 1 dari segi tingkat akurasi dan tingkat deteksi serangan, akan tetapi dari segi tingkat false positive model 1 memiliki tingkat false positive yang lebih baik dari pada model 2 .

Tabel 5 Perbandingan performansi model pada pengujian real-time

\begin{tabular}{|l|l|l|l|}
\hline \multicolumn{1}{|c|}{ Model } & $\begin{array}{c}\text { Tingkat } \\
\text { Akurasi (\%) }\end{array}$ & $\begin{array}{c}\text { Tingkat } \\
\text { Deteksi Intrusi } \\
(\mathbf{\%})\end{array}$ & $\begin{array}{c}\text { Tingkat False } \\
\text { Positive (\%) }\end{array}$ \\
\hline Model 1 & $86,38 \%$ & 82,05 & 7,17 \\
\hline Model 2 & $89,68 \%$ & 88,37 & 8,63 \\
\hline
\end{tabular}

Tabel 6 menunjukkan perbandingan kemampuan pendeteksian serangan pada tiap-tiap aksi intrusi yang dilakukan.

Tabel 6 Perbandingan attack detection rate secara real-time

\begin{tabular}{|c|c|c|c|c|c|c|c|c|c|}
\hline \multirow{3}{*}{ No } & \multirow{3}{*}{ Intrusi } & \multirow{3}{*}{$\begin{array}{l}\text { Tipe } \\
\text { Intrusi }\end{array}$} & \multirow{3}{*}{$\begin{array}{l}\text { Jumlah } \\
\text { Record }\end{array}$} & \multicolumn{4}{|c|}{ Hasil klasifikasi } & \multirow{2}{*}{\multicolumn{2}{|c|}{$\begin{array}{c}\text { Attack } \\
\text { Detection } \\
\text { Rate }(\%)\end{array}$}} \\
\hline & & & & \multicolumn{2}{|c|}{ Benar } & \multicolumn{2}{|c|}{ Salah } & & \\
\hline & & & & M1 & M2 & M1 & M2 & M1 & M2 \\
\hline 1 & Intense Scan & \multirow{8}{*}{ Probe } & 545 & 541 & 533 & 4 & 12 & 99,27 & 97,80 \\
\hline 2 & $\begin{array}{l}\text { Intense Scan } \\
\text { Plus UDP }\end{array}$ & & 1945 & 624 & 1530 & 1321 & 415 & 32,08 & 78,66 \\
\hline 3 & $\begin{array}{l}\text { Intense Scan All } \\
\text { TCP Ports }\end{array}$ & & 3534 & 3481 & 3483 & 53 & 51 & 98,50 & 98,56 \\
\hline 4 & $\begin{array}{l}\text { Intense Scan No } \\
\text { Ping }\end{array}$ & & 391 & 387 & 379 & 4 & 12 & 98,98 & 96,93 \\
\hline 5 & Reguler Scan & & 457 & 447 & 442 & 10 & 15 & 97,81 & 96,72 \\
\hline 6 & Quick Scan & & 227 & 216 & 211 & 11 & 16 & 95,15 & 92,95 \\
\hline 7 & Quick Scan Plus & & 284 & 257 & 229 & 27 & 55 & 90,49 & 80,63 \\
\hline 8 & $\begin{array}{l}\text { Slow } \\
\text { Comprehensive } \\
\text { Scan }\end{array}$ & & 2645 & 453 & 1869 & 2192 & 776 & 17,13 & 70,66 \\
\hline 9 & Ping -17500 & \multirow{5}{*}{ DoS } & 3030 & 2807 & 2834 & 223 & 196 & 92,64 & 93,53 \\
\hline 10 & Hping & & 2896 & 2508 & 2482 & 388 & 414 & 86,60 & 85,70 \\
\hline 11 & Letdown & & 3368 & 2876 & 2848 & 492 & 520 & 85,39 & 84,56 \\
\hline 12 & UDP.pl & & 3852 & 3676 & 3729 & 176 & 123 & 95,43 & 96,81 \\
\hline 13 & Slowloris & & 2003 & 1546 & 1507 & 457 & 496 & 77,18 & 75,24 \\
\hline
\end{tabular}

IJCCS Vol. 8, No. 1, January 2014: 13 - 24 
Dari Tabel 6 dapat dilihat bahwa model 1 memiliki kemampuan pendeteksian serangan yang lebih baik daripada model 2 pada sebagian besar intrusi yang dilakukan, akan tetapi pada beberapa intrusi model 2 menunjukkan performansi yang jauh lebih baik daripada model 1 yaitu pada aksi intrusi Intense Scan Plus UDP dan Slow Comprehensive Scan, hal ini yang menyebabkan turunnya performansi dari model 1 dibandingkan model 2.

\section{KESIMPULAN}

Berdasar hasil-hasil pengujian dari sistem yang telah dibangun dapat ditarik kesimpulan bahwa:

1. Penerapan metode klasifikasi support vector machine dalam sistem deteksi intrusi yang telah dibangun dapat membantu analis dalam pembentukan profile, skenario intrusi atau model secara otomatis, dimana dari hasil pengujian model yang dihasilkan oleh sistem ini dapat mendeteksi aksi intrusi yang dilakukan dengan tingkat akurasi dan tingkat deteksi yang tinggi, serta tingkat false positive yang rendah.

2. Pengujian secara real-time membuktikan bahwa penerapan fungsi complete/incomplete connection record dalam proses preprocessing pembentukan data audit atau connection record dapat menjadi solusi permasalahan keterlambatan pendeteksian akibat durasi koneksi yang terlalu lama.

3. Dari hasil pengujian secara real-time, sistem belum dapat mendeteksi secara efektif aksi intrusi ketika aksi tersebut baru mulai dilakukan, connection record yang terbentuk pada saat aksi intrusi baru dilakukan masih diklasifikasikan dengan kelas normal, kondisi ini tidak hanya mempengaruhi tingkat pendeteksian serangan tapi juga memberi celah bagi aksi-aksi intrusi yang dilakukan dengan mengirim paket data secara lambat.

\section{SARAN}

Disadari bahwa aplikasi ini masih memiliki kelemahan-kelemahan yang membutuhkan pengembangan lanjutan untuk membuatnya menjadi lebih baik, sehingga untuk selanjutnya diharapkan dapat dilakukan hal-hal berikut untuk memperbaikinya:

1. Perbaikan pada proses pembentukan connection record. Pada proses pembentukan fitur connection record masih belum bisa ditentukan dengan benar mana yang menjadi source host dan destination host. Source host dan destination host masih didasarkan pada informasi yang ditemukan pertama kali, sehingga akibat penerapan incomplete connection record kemungkinan untuk salah mendefinisikan source host dan destination host menjadi besar yang berakibat pada kesalahan klasifikasi.

2. Perlu dilakukan penelitian untuk metode penentuan parameter SVM. Berdasar hasil pengujian dapat dilihat bahwa penentuan parameter SVM yang tepat dapat memberikan model dengan performansi yang baik dan untuk mendapatkannya perlu dilakukan pengujian berulang-ulang dengan kombinasi parameter yang berbeda. Pencarian parameter yang dilakukan dengan mencoba kombinasi parameter satu persatu sangat tidak efisien dari segi waktu dan belum tentu akan mendapatkan model dengan performansi terbaik.

3. Pengembangan penelitian untuk ekstraksi informasi payload atau isi dari data yang ditransmisikan. Sistem yang dibangun baru bisa mendeteksi intrusi berdasar informasi header paket data, dengan adanya penelitian ekstraksi informasi payload diharapkan dapat dibentuk fitur-fitur baru untuk pendeteksian intrusi pada level aplikasi seperti cross site scripting dan SQL injection. 


\section{DAFTAR PUSTAKA}

[1] Lee, W., 1999. A Data Mining Framework for Constructing Features and Models for Intrusion Detection Sistems, Tesis, School of Arts and Sciences Columbia University, New York

[2] Bloedorn E., Christiansen,D., Hill, W., Skorupka, C., Talbot, L., dan Tivel, J., 2001, Data Mining for Network Intrusion Detection: How to Get Started, MITRE Technical Report, Agustus 2001

[3] Agathou A. dan Tzouramanis, T., 2008, The Role Of Data mining in Intrusion Detection Technology, Garson, G.D. dan Khosrow-Pour,M (ed.), Handbook of Research on Public Information Technology, Vol.1, Information Science Reference, Hershey,New York

[4] Tavallaee, M., Bagheri, E., Lu, W., dan Ghorbani, A. A., 2009, A Detailed Analysis of the KDD CUP 99 Data Set, Proceedings of the 2009 IEEE Symposium on Computational Intelligence in Security and Defense Applications (CISDA 2009)

[5] Shrivastava, K. S., dan Jain, P., 2011, Effective Anomaly Based Intrusion Detection using Rough Set Theory and Support Vector Machine, International Journal of Computer Applications, Vol.18-No 3, hal 35-41

[6] Han, J., dan Kamber, M., 2006, Data mining: Concepts and Techniques, Ed.2 Morgan Kaufmann Publishers, San Francisco, USA

[7] Benferhat, S., Sedki, K., dan Tabia, K., 2007. Preprocessing Rough Network Traffic For Intrusion Detection Purposes. IADIS International Telecommunications, Networks and Sistems 2007, hal.105-109. 